\title{
Considerations on patient-related outcomes with the use of botulinum toxins: is switching products safe?
}

\author{
Avram Fraint ${ }^{1}$ \\ Padmaja Vittal ${ }^{2}$ \\ Cynthia Comella ${ }^{2}$ \\ 'Department of Neurological \\ Sciences, ${ }^{2}$ Section of Movement \\ Disorders, Rush University Medical \\ Center, Chicago, IL, USA
}

This article was published in the following Dove Press journal:

Therapeutics and Clinical Risk Management

5 February 2016

Number of times this article has been viewed

Introduction: Botulinum toxin $(\mathrm{BoNT})$ is the treatment of choice for many neurologic movement disorders, including blepharospasm, hemifacial spasm, and cervical dystonia. There are two serotypes approved for use by the US Food and Drug Administration: three brands of serotype A and one of serotype B. Many attempts have been made at establishing dose conversion ratios between brands and serotypes. This review focuses on the existing data comparing different formulations of the same BoNT serotypes as well as that comparing different serotypes with one another. We focus on existing data regarding switching from one formulation or serotype to another and will also discuss the issue of immunogenicity of BoNT. With this information as a foundation, recommendations on safety of switching agents are addressed.

Method: Literature review searching PubMed and Google Scholar using the search terms "switching botox", "dosing equivalency in botox", and "comparing botox".

Results/conclusion: Overall, there are many studies that demonstrate the efficacy and safety of each of the brands of BoNTs used in clinical practice. However, determination of dosing equivalencies among these brands and serotypes is complex with inconsistencies among the studies. When switching from one brand to another, the clinician should be aware of these issues, and not make the assumption that such ratios exist. Tailoring the dosage of each brand of BoNT to the clinical situation is the most prudent treatment strategy rather than focusing closely on conversion factors and concerns for immunogenicity.

Keywords: botulinum toxin, BoNT, abobotulinumtoxin A, onabotulinumtoxin A, incobotulinumtoxin $\mathrm{A}$, rimabotulinumtoxin $\mathrm{B}$

\section{Introduction}

Botulinum toxin (BoNT) is the treatment of choice for many neurologic movement disorders, including blepharospasm (BPS), hemifacial spasm (HFS), and cervical dystonia (CD). The toxin owes its efficacy in these disorders to inhibition of acetylcholine (ACh) release from nerve terminals into the neuromuscular junction, thus preventing neuromuscular conduction and muscle contraction. ${ }^{1,2}$ Under normal circumstances, ACh release into the neuromuscular junction occurs via fusion of ACh-containing vesicles with the presynaptic membrane. Fusion occurs via formation of a synaptic fusion complex made up of soluble $N$-ethylmaleimide-sensitive factor attachment protein receptor (SNARE) proteins. SNARE proteins form a complex of three proteins, two of which are targeted specifically by different BoNT serotypes. These three proteins include syntaxin 1 , synaptosomal-associated protein 25 , and synaptobrevin, and they mediate docking and exocytosis of ACh vesicles at the presynaptic nerve terminal. ${ }^{1}$

The different BoNT serotypes have different complex protein structures. The exact composition and size of the protein complex depends on the serotype and the strain of
Correspondence: Avram Fraint Department of Neurological Sciences, Rush University Medical Center, I725 W Harrison St, Suite II I8, Chicago, IL 606I2, USA

Email avram_fraint@rush.edu cc) (i) () 2016 Fraint et al. This work is published and licensed by Dove Medical Press Limited. The full terms of this license are available at https://www.dovepress.com/tterms.php and incorporate the Creative Commons Attribution - Non Commercial (unported, v3.0) License (http://creativecommons.org/licensess/by-nc/3.0/). By accessing the work you

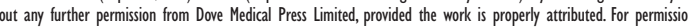
for commercial use of this work, please see paragraphs 4.2 and 5 of our Terms (https://www.dovepress.com/terms.php). 
Table I Types of botulinum toxin

\begin{tabular}{llllll}
\hline Generic name & $\begin{array}{l}\text { Trade } \\
\text { name }\end{array}$ & Serotype & $\begin{array}{l}\text { Molecular } \\
\text { weight (kDa) }\end{array}$ & Target & Manufacturer \\
\hline Onabotulinumtoxin A & Botox & A & 900 & SNAP-25 & Allergan, Inc. (Irvine, CA, USA) \\
Abobotulinumtoxin A & Dysport & A & $500-900$ & SNAP-25 & Ipsen Biopharmaceuticals, Inc. (Paris, France) \\
Incobotulinumtoxin A & Xeomin & A & 150 & SNAP-25 & Merz Pharmaceuticals (Frankfurt, Germany) \\
Rimabotulinumtoxin B & Myobloc & B & 700 & Synaptobrevin & Solstice Neurosciences (US WorldMeds; \\
& & & & & Louisville, KY, USA)
\end{tabular}

Abbreviation: SNAP-25, synaptosomal-associated protein 25.

Clostridium botulinum that produces it. Although all BoNT serotypes inhibit ACh release, each serotype cleaves specific proteins of the SNARE complex or different sites on the same protein, making the serotypes distinct from each other and giving them different pharmacologic profiles. ${ }^{1}$ There are two serotypes approved for use by the United States Food and Drug Administration: three brands of serotype A (BoNT-A) and one of serotype B (BoNT-B) (Table 1).

There are three commercially available types of BoNT-A, all of which target the synaptosomal-associated protein 25 receptor. Onabotulinumtoxin A (Onabot; trade name Botox) is made by Allergan, Inc. (Irvine, CA, USA) and has a molecular weight of $900 \mathrm{kDa}$. Abobotulinumtoxin A (Abobot; trade name Dysport) is manufactured by Ipsen Biopharmaceuticals, Inc. (Paris, France) and has a molecular weight between 500 and $900 \mathrm{kDa}$. Incobotulinumtoxin A (Incobot; trade name Xeomin) is manufactured by Merz Pharmaceuticals (Frankfurt, Germany) and has a molecular weight of $150 \mathrm{kDa}$. The one commercially available BoNT-B is rimabotulinumtoxin B (Rimabot; trade name Myobloc) and is manufactured by Solstice Neurosciences (US WorldMeds; Louisville, KY, USA). This formulation has a molecular weight of $700 \mathrm{kDa}$ and targets synaptobrevin. ${ }^{2}$

Potency of BoNT varies from one species to another, and there are differences in potency among the commercially available formulations as measured in mouse units. A mouse unit is the amount of toxin needed to kill $50 \%$ of a group of a specific species of mouse within 3 days of intraperitoneal injection. ${ }^{3}$ A clinically effective dose of Rimabot is several orders of magnitude higher than that of Onabot. ${ }^{4}$ Even within the same serotype, potency can vary significantly, suggesting that there are factors beyond serotype which affect potency. ${ }^{1}$ Onabot is said to be two to six times more potent per unit than Abobot, even though they are both of serotype A. The factors that influence potency include: manufacturing process and protein (albumin) content. Factors that may alter clinical effect include: dilution, concentration, injection technique, and immunoresistance. ${ }^{5}$

The assay for BoNT-A used in the USA uses saline and no protein carrier, whereas that in the UK uses a phosphate buffer containing gelatin to stabilize low concentrations of the toxin. Further complicating the issue is that use of BoNT for different indications may require different dosing equivalencies, since $\mathrm{CD}$ is considered a more clinically sensitive dosing model compared with BPS and HFS. ${ }^{6}$ For this reason, many attempts have been made to establish dosing equivalencies both within and across serotypes, for all different indications. These attempts have produced varying results. This review will focus on the existing data comparing different formulations of the same BoNT serotypes as well as that comparing different serotypes with one another. We will focus on existing data regarding switching from one formulation or serotype to another and will also discuss the issue of immunogenicity of BoNT. With this information as a foundation, recommendations on safety of switching agents will be addressed.

\section{Comparative studies Abobot and Onabot}

The issue of dosing equivalence is important when specific toxins may not be available or when side effects emerge, and transition to other toxins becomes necessary. The widest range of suggested dosing equivalencies exists when comparing Abobot and Onabot (Table 2).

In 1997, Nussgens and Roggenkamper ${ }^{7}$ conducted a double-blind study of 212 consecutive patients with BPS. At a first treatment session, patients were randomly assigned to receive either one injection of Onabot or one injection of Abobot. At a second session, they were crossed over to receive the other brand at a ratio of one unit of Onabot for every four units of Abobot. The average dose of Onabot

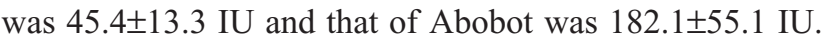
The study found no significant difference in duration of therapeutic effect, suggesting a bioequivalence of 1:4 IU. However, this study reported that side effects (such as ptosis, eye tearing, blurry vision, diplopia, hematoma, and sensation of foreign body) were more common in the patients who received Abobot.

Sampaio et $\mathrm{al}^{8}$ used the same 1:4 ratio when designing a single-blind, randomized, parallel comparison trial of Onabot and Abobot in patients with BPS or HFS. Ninety-one patients 
Table 2 Comparing Onabot and Abobot

\begin{tabular}{|c|c|c|c|c|}
\hline Study & Indication & Dosing ratio & Efficacy & Tolerability \\
\hline Sampaio et $\mathrm{al}^{8}$ & BPS, HFS & $\mathrm{I}: 4$ & Equal & Equal \\
\hline Nussgens and Roggenkamper ${ }^{7}$ & BPS, HFS & $\mathrm{I}: 4$ & Equal & Onabot $>$ Abobot \\
\hline Odergren et $\mathrm{al}^{9}$ & $C D$ & $\mathrm{I}: 3$ & Equal & Equal \\
\hline Ranoux et $\mathrm{al}^{34}$ & $C D$ & $\mathrm{I}: 3$ and $\mathrm{I}: 4$ & Abobot $>$ Onabot & Onabot $>$ Abobot \\
\hline Bihari $^{24}$ & BPS, CD, or HFS & $\mathrm{I}: 4$ to $\mathrm{I}: 5$ & Onabot $>$ Abobot & Onabot $>$ Abobot \\
\hline Marchetti et $\mathrm{al}^{25}$ & $\mathrm{BS}$ or $\mathrm{CD}$ & $\mathrm{I}: 2$ to $\mathrm{I}: \mathrm{I} \mathrm{I}$ & NA & Onabot $>$ Abobot \\
\hline Bentivoglio et $\mathrm{al}^{13}$ & BPS or HFS & $\mathrm{I}: \mathrm{I} .2$ to $\mathrm{I}: \mathrm{|} 3.3$ & Equal & Equal \\
\hline
\end{tabular}

Abbreviations: Abobot, abobotulinumtoxin A; BPS, blepharospasm; CD, cervical dystonia; HFS, hemifacial spasm; NA, not available; Onabot, onabotulinumtoxin A.

were randomized to treatment with either Abobot or Onabot and evaluated at baseline, 4 weeks posttreatment, and then whenever the effect of the toxin was judged to be fading. Both groups had similar efficacy and tolerated the treatments equally well without differences in adverse effects. However, a larger portion (23\%) of the patients who received Abobot needed a booster treatment compared with $12 \%$ of the group who received Onabot.

Odergren et $\mathrm{a}^{9}$ conducted a double-blind study investigating the effect of a 1:3 ratio of Onabot to Abobot in treatment of CD. A total of 73 patients were enrolled, all of whom had already been treated with at least four prior doses of Onabot. Patients were randomized to receive either the clinically effective dose of Onabot derived from prior injections or three times that dose of Abobot. Patients were assessed 2, 4, 8, and 12 weeks after treatment. Both groups showed substantial and similar improvement at 2 weeks, with peak effect at 4 weeks. Duration of therapeutic effect and time to retreatment were similar as well. This study suggested that a 1:3 (Onabot:Abobot) ratio may be reasonable for treatment of CD.

Wohlfarth et a ${ }^{10}$ conducted a study using electromyography to compare dose equivalencies, diffusion characteristics, and safety of Onabot and Abobot. Seventy-nine patients were randomized to receive either medication using a 1:3 (Onabot:Abobot) dosing equivalence ratio. Patients were injected in the extensor digitorum brevis (EDB) muscle and their compound muscle action potential (CMAP) amplitudes were measured 2 and 12 weeks after injection. The study found that CMAP amplitude reductions were equal in both groups, and that both groups had persistent effects at 12-week follow-up. For both groups, CMAP amplitude was increasingly reduced as the dose or concentration of BoNT was increased. Statistical modeling with the CMAP amplitude data from the target muscle gave a bioequivalence of 1:1.57 (Onabot:Abobot) (95\% confidence interval: 0.77-3.2 units). The study concluded that an equivalence ratio of 1:3 was within the statistical error limits.
Kranz et a ${ }^{11}$ compared Onabot and Abobot as well, but used two different equivalency ratios. This double-blind, randomized trial employed a three-period crossover design in 54 patients with $\mathrm{CD}$. Patients were randomized to three groups: Onabot at the usual recommended dose, Abobot at a ratio of 1:3 (Onabot:Abobot), and Abobot at a ratio of 1:4 (Onabot:Abobot). Objective assessments, including the Tsui rating scale and the Toronto Western Spasmodic Torticollis Rating Scale (TWSTRS) scores were obtained at baseline and 1 month after each of three separate injections. Adverse effects were also assessed. Tsui scores and TWSTRS scores showed greater improvement in the Abobot 1:3 and 1:4 groups compared with the Onabot group. The number of adverse events, however, was higher in both Abobot groups, with the most frequent being dysphagia (found in $3 \%$ of the Onabot group and in $15.6 \%$ and $17.3 \%$ of the two Abobot groups, respectively). This study concluded that Abobot in a 1:3 (Onabot:Abobot) ratio was likely optimal. Although the 1:4 (Onabot:Abobot) ratio was more effective in improving function and decreasing CD-related pain, there was a greater risk for adverse events. The study posited that the most appropriate conversion factor between Onabot and Abobot could be less than 1:3.

Rystedt et al $^{12}$ conducted a double-blind, randomized crossover trial comparing Onabot and Abobot using two different dosing ratios, 1:3 (Onabot:Abobot) and 1:1.7 (Onabot:Abobot) in patients with CD. A total of 46 patients with $\mathrm{CD}$ were given three different treatments - Onabot in two different doses and Abobot as control. Efficacy was evaluated 4 and 12 weeks after treatment. The TWSTRS total score was 1.96 points higher for Onabot at 1:3 dosing compared with Abobot at week 4, though the difference was not statistically significant. At 12 weeks, however, there was a statistically significant difference for this dosing regimen. No differences were observed when comparing Onabot at 1:1.7 dosing with Abobot. This study also suggested that the dose conversion ratio between Abobot and Onabot may be lower than $1: 3 .^{12}$ 
It is clear from the studies above that a dosing equivalency between Onabot and Abobot has not been clearly established. Both formulations are clinically effective, but because sideeffect profiles differ at different dosing ratios, the two brands should be considered distinct from one another, and a true bioequivalence might not exist. ${ }^{13,14}$

\section{Incobot and Onabot}

Incobot is the most recently approved BoNT in the USA. It differs from Onabot in that it lacks complexing proteins. It is unclear, however, whether this difference confers Incobot any advantage for clinical use. There have been multiple studies comparing these two brands (Table 3).

In 2005, Benecke et al ${ }^{15}$ investigated Incobot compared with Onabot in a double-blind, parallel-group, noninferiority trial. There were $463 \mathrm{CD}$ patients included. Patients were randomized to receive Incobot or Onabot at a 1:1 dosing ratio. In this study, Incobot was found to be noninferior to Onabot, and was equally well-tolerated.

Building on these findings, Wabbels et $\mathrm{al}^{16}$ conducted a double-blind, randomized, parallel-group pilot study comparing the efficacy of Incobot and Onabot in patients with BPS. A total of 65 subjects were randomly assigned to receive either one of these medications at a dose equal to that of their most recent treatment. Treatment with both types of BoNT-A products reduced scores on the BPS disability index as well as the Jankovic rating scale. At 4 and 8 weeks postinjection, there was no difference in observed improvements nor in frequency of adverse events between the two preparations.

Saad and Gourdeau ${ }^{17}$ compared Onabot and Incobot in treatment of BPS. This prospective, randomized, doubleblind study included 48 patients, all previously treated with Onabot. The study employed a "split-face" technique, wherein half of the patients received Incobot on the right and Onabot on the left side of their faces, and vice versa for the other half. There was no difference found between the two toxins for both subjective or objective measures of BPS.

The first long-term, open-label study comparing all three types of commercially available BoNT-A was performed by
Kollewe et $\mathrm{al}^{18}$ in 2015 . This study compiled efficacy and tolerability data in 288 patients with BPS treated with one of the three BoNT-A preparations for at least eight consecutive treatments. Doses of Onabot were $47 \pm 10$ mouse units, while doses of Abobot were 120 \pm 32 mouse units, and doses of Incobot were $62 \pm 11$ mouse units. Patients were treated over 11.2 \pm 4.1 years, and a total of 10,701 injection series were evaluated. The study found no statistically significant difference in onset of therapeutic effect, global clinical improvement, and frequency of adverse events among the three groups. All three products resulted in a significant clinical improvement, with onset of therapeutic effect about 6 days after injection and lasting about 10 weeks before it started to wane.

Dressler et al ${ }^{19}$ compared efficacy of Onabot with that of Incobot in the treatment of CD using a crossover study design. Forty patients with CD were included. Each patient was injected with Onabot and then Incobot for at least four injection series, using a 1:1 dosing ratio. Efficacy was equal for both formulations, confirming the adequacy of a $1: 1$ dosing conversion.

\section{Different serotypes}

Comparison of different serotypes of BoNT is problematic given differences in mechanism of action, potency, and side-effect profile. Sloop et $\mathrm{al}^{20}$ compared human muscle paralysis resulting from injections of BoNT-A and BoNT-B. Seventeen healthy volunteers were injected with 17 different doses of BoNT-B (with doses ranging from 1.25 to 480 units). Researchers established a dose-response curve for BoNT-B by measuring EDB M wave amplitudes before and after injections over a 57-week period. They then compared this dose-response curve with a previously published doseresponse curve for BoNT-A. To this end, ten new volunteers were injected with BoNT-A in one EDB, and with BoNT-B in the opposite EDB using five different doses of each toxin serotype. Efficacy of the injection was expressed as a percent decline in the $\mathrm{M}$ wave amplitude after injection, or percent muscle paralysis. Maximal paralysis 2 weeks after injection with 320-480 mouse units of BoNT-B was 50\%-75\%, whereas maximal paralysis at 2 weeks postinjection with

Table 3 Comparing Onabot and Incobot

\begin{tabular}{|c|c|c|c|c|}
\hline Study & Indication & Dosing ratio & Efficacy & Other \\
\hline Wabbels et al $^{16}$ & BPS & $\mathrm{I}: \mathrm{I}$ & Equal & No difference in frequency of adverse events \\
\hline Saad and Gourdeau ${ }^{17}$ & BPS & $\mathrm{I}: \mathrm{I}$ & Equal & Used the "split-face" technique \\
\hline Dressler et al $^{19}$ & CD & $\mathrm{I}: \mathrm{I}$ & Equal & \\
\hline
\end{tabular}

Abbreviations: BPS, blepharospasm; CD, cervical dystonia; Incobot, incobotulinumtoxin A; Onabot, onabotulinumtoxin A. 
7.5-10 mouse units of BoNT-A was 70\%-80\%. This study demonstrated that much higher doses of BoNT-B must be given to obtain similar degrees of muscle paralysis compared with BoNT-A. The study also indicated that BoNT-B injections produce less effective neuromuscular blockade and a shorter duration of paralysis.

Comella et $\mathrm{al}^{21}$ aimed to directly compare Onabot and Rimabot in treatment of CD. This randomized, doubleblind, parallel-arm study included a total of 139 patients with CD who had been previously treated with Onabot. Subjects were randomly assigned to receive either Onabot or Rimabot in a double-blinded fashion using a dosing ratio of 50:1. Patients were assessed before injection and at regular intervals after injection. Assessments were discontinued after either a loss of $80 \%$ clinical efficacy or 20 weeks after injection. Improvement in the TWSTRS scale at 4 weeks postinjection was the same for both serotypes, though dysphagia and dry mouth were more common with Rimabot. Those receiving Onabot had a modestly longer duration of therapeutic effect.

Pappert et $\mathrm{a}^{22}$ performed a randomized, double-blind, noninferiority trial in 2008 comparing Onabot and Rimabot in toxin-naïve patients with $\mathrm{CD}$. A total of 111 patients were randomized to receive either Onabot or Rimabot in a dosing ratio of 67:1 and evaluated at baseline and every 4 weeks after injection. Improvement in the total TWSTRS scores 4 weeks postinjection did not differ between Onabot and Rimabot. The two formulations had a similar median duration of effect, and there were no observed differences in side effects, except that mild dry mouth was more frequent with Rimabot. From this study, it was concluded that Rimabot was not inferior to Onabot.

\section{Switching studies}

Switching toxin strains may be necessary when changing physicians, when patient insurance indicates specific preferences, or in the event of secondary treatment failure resulting from presumed immune resistance. In 1999, Brin et $\mathrm{al}^{23}$ studied the safety and efficacy of using BoNT-B in patients with clinical resistance to Onabot - either demonstrating no clinical response or no response to the frontalis type A test. The study was a 16-week, double-blind, randomized placebocontrolled trial, in which 77 patients were treated with either placebo or 10,000 units of Rimabot into involved muscles. At 16 weeks, patients who received Rimabot showed improvement in severity, disability, and pain (as rated using the TWSTRS) compared with the placebo group. Patients who received Rimabot reported more frequent dry mouth and dysphagia. This study demonstrated that Rimabot may be a good alternative for patients with secondary treatment failure to Onabot (Table 4).

Bihari ${ }^{24}$ conducted a prospective observational study to compare the safety, efficacy, and duration of effect of switching from Abobot to Onabot. Forty-eight patients were enrolled (27 with BPS, 12 with CD, and nine with HFS) in this single-arm study. Patients received an injection of Abobot and were assessed over 12 weeks of follow-up. They were then given an injection of Onabot, with dosing ratios (Abobot:Onabot) of 4:1 for BPS or 5:1 for CD or HFS and followed for 12 weeks. Patients were assessed with scales appropriate to their disease at baseline, 3 weeks, and 12 weeks after injection. The study found greater clinical improvement (based on Jankovic rating scale and TWSTRS) in the patients with BPS and CD in the group who received Onabot. Patients with HFS also self-reported greater improvement with

Table 4 Switching studies

\begin{tabular}{|c|c|c|c|c|c|}
\hline Study & Indication & Methods & Details & Efficacy & Other \\
\hline Brin et $\mathrm{al}^{23}$ & $C D$ & $\begin{array}{l}\text { Giving BoNT-B to } \\
\text { Onabot failures }\end{array}$ & $\begin{array}{l}\text { Placebo or } 10,000 \\
\text { units BoNT-B }\end{array}$ & Equal & $\begin{array}{l}\text { More dry mouth and dysphagia } \\
\text { in BoNT-B }\end{array}$ \\
\hline Bihari ${ }^{24}$ & $\begin{array}{l}\text { BPS, HFS, } \\
\text { CD }\end{array}$ & $\begin{array}{l}\text { Compared Abobot } \\
\text { with Onabot }\end{array}$ & $\begin{array}{l}\text { Dose ratio of } 4: 1 \text { for } \\
\text { BPS and } 5: I \text { for CD } \\
\text { and HFS }\end{array}$ & $\begin{array}{l}\text { Onabot }>\text { Abobot for all three } \\
\text { indications }\end{array}$ & $\begin{array}{l}\text { Longer duration of benefit for } \\
\text { Onabot, more adverse events } \\
\text { for Abobot }\end{array}$ \\
\hline $\begin{array}{l}\text { Marchetti } \\
\text { et al }{ }^{25}\end{array}$ & $C D, B P S$ & $\begin{array}{l}\text { Compared Abobot } \\
\text { with Onabot }\end{array}$ & $\begin{array}{l}\text { Dosing ratios ranges } \\
\text { from } 2: 1 \text { to } 11: 1\end{array}$ & $\begin{array}{l}\text { Abobot was equally effective over } \\
\text { a range of doses }\end{array}$ & $\begin{array}{l}\text { Could not recommend a fixed } \\
\text { dosing ratio }\end{array}$ \\
\hline $\begin{array}{l}\text { Badarny } \\
\text { et } \mathrm{al}^{35}\end{array}$ & BPS, HFS & $\begin{array}{l}\text { Compared Onabot } \\
\text { with Abobot }\end{array}$ & $\begin{array}{l}\text { Used conversion ratio } \\
\text { of } 1: 3 \text { or } 1: 4\end{array}$ & $\begin{array}{l}\text { Two patients who never responded } \\
\text { to Onabot did respond to Abobot. } \\
\text { Two patients with secondary failure } \\
\text { to Onabot responded to Abobot }\end{array}$ & $\begin{array}{l}\text { Onabot and Abobot have } \\
\text { different pharmacologic and } \\
\text { biological activity, and should be } \\
\text { considered different medications }\end{array}$ \\
\hline $\begin{array}{l}\text { Dutton } \\
\text { et } \mathrm{al}^{26}\end{array}$ & BPS, HFS & $\begin{array}{l}\text { Switching from } \\
\text { Onabot to Rimabot }\end{array}$ & $\begin{array}{l}\text { Average dose of } 3,633 \\
\text { units of Rimabot per } \\
\text { session over } 7.3 \text { weeks }\end{array}$ & $\begin{array}{l}\text { Response rated as } \\
\text { "fair to excellent" }\end{array}$ & $\begin{array}{l}\text { More side effects with Rimabot } \\
\text { and a shorter duration of benefit }\end{array}$ \\
\hline
\end{tabular}

Abbreviations: Abobot, abobotulinumtoxin A; BoNT, botulinum toxin; BPS, blepharospasm; CD, cervical dystonia; HFS, hemifacial spasm; Onabot, onabotulinumtoxin; Rimabot, rimabotulinumtoxin $B$. 
Onabot compared with Abobot. Longer duration of benefit was observed for Onabot for all three disorders, and while there were 19 adverse events reported in the Abobot group, there were none reported after treatment with Onabot.

The REAL DOSE (retrospective evaluation of the dose of Dysport and Botox in the management of cervical dystonia and blepharospasm) study was a retrospective, observational review study published in 2005 evaluating the real-world dose utilization of Abobot and Onabot in CD and BPS. Six investigational sites in five countries participated in compiling data via chart review for patients who received Abobot and were then switched to Onabot or vice versa. A total of 114 patients were included, 70 with CD and 44 with BPS or HFS. They found that the dosing ratios ranged from 2:1 to $11: 1$, and concluded that there was not a fixed dose conversion ratio, but that clinical decisions for dosing requires a case-by-case evaluation. ${ }^{25}$

Dutton et $\mathrm{al}^{26}$ studied patients with BPS and HFS with secondary treatment failure with Onabot, and their response when switched to Rimabot. Total 16 patients were evaluated, receiving an average dose of 3,633 units per treatment session. The mean duration of benefit after switching toxins was 7.3 weeks and the response was most commonly rated as fair to excellent. There were, however, more side effects reported with Rimabot compared with Onabot and a shorter overall duration of benefit as well.

Bentivoglio et $\mathrm{al}^{13}$ retrospectively studied patients treated between 1986 and 2003 with diagnoses of BPS and HFS who received Onabot or Abobot in at least two consecutive treatments. The study identified 56 patients with BPS and 31 patients with HFS who switched from one brand of BoNT-A to the other. In both groups, no statistically significant difference in outcome measures was observed. The study concluded that a conversion factor between these two formulations should only be considered an equivalence in terms of magnitude of clinical improvement, rather than a true bioequivalence. This is most likely due to intrinsic pharmacokinetic differences in these two products. ${ }^{13}$

These studies suggest that switching from one serotype to another may be effective in patients with clinical resistance to one serotype. Further, when switching from one brand to another of serotype A, similar outcomes should be anticipated.

\section{Immunogenicity}

The clinical significance of the presence of neutralizing antibodies to BoNT is unclear, but is an important consideration given that BoNT treatment requires repeated injections over a prolonged period. The presence of these antibodies, however, does not always render patients nonresponsive. It may be that complexing proteins act as adjuvants which stimulate an immune response. ${ }^{27}$ This issue is particularly problematic in treatment of $\mathrm{CD}$, which requires injection into large muscles, and usually escalating doses to achieve therapeutic effect. The incidence of antibody formation when using BoNT-A is estimated at less than $5 \%{ }^{1}$

In 2006, Jankovic et $\mathrm{al}^{28}$ used the mouse protection assay to detect neutralizing antibodies to Rimabot (serotype B) in treatment of CD. Over 42 months of observation, one-third of patients developed antibodies to BoNT-B, but the study did not include indications of whether these patients continued to respond clinically. The study indicated that cross-reactivity between the serotypes is not an important determinant of the risk of developing antibodies to BoNT-B, though there was a high frequency of de novo development of antibodies to BoNT-B.

Kranz et $\mathrm{al}^{29}$ tested whether neutralizing antibodies to BoNT-A could be detected in dystonic patients with good clinical response to BoNT-A. They compared responses of a sweat test and a mouse diaphragm test in 14 subjects who responded to BoNT-A with those of 14 healthy controls. Higher BoNT-A antibody titers correlated significantly with smaller anhidrotic areas, and poor therapeutic response. Furthermore, more than $40 \%$ of dystonic subjects who responded well to BoNT-A showed partial nonresponsiveness on the sweat test and had low neutralizing antibodies to BoNT-A, again suggesting a dissociation between the presence of antibodies and a good clinical effect.

Brin et $\mathrm{al}^{30}$ evaluated the long-term immunogenicity of Onabot in CD patients who had no previous treatment with any BoNT. This was a prospective, open-label, multicenter study. Serum samples were analyzed for BoNT-A neutralizing antibodies using the mouse protection assay. Subjects received a median of nine BoNT-A treatments over a mean of 2.5 years. Only four of the 326 subjects (1.2\%) were found to have neutralizing antibodies, but were initially rated as responders. Subsequent testing showed that the antibodies had disappeared. However, three patients stopped responding clinically to BoNT-A. The study concluded that development of neutralizing antibodies to BoNT-A is rare and may not correlate with clinical responsiveness. Lange et $\mathrm{al}^{31}$ evaluated serum samples from 503 patients with secondary nonresponse to BoNT. They found that in this group, less than half had evidence of neutralizing antibodies, suggesting that immunoresistance is not the most important factor in clinical nonresponse. 
Charles et $\mathrm{al}^{32}$ evaluated efficacy, tolerability, and formation of neutralizing antibodies to Onabot in treatment of CD. This randomized, multicenter, placebo-controlled trial was the first to analyze the effects of Onabot versus placebo to also include analysis of the neutralizing antibody status. Subjects were given Onabot over a 10-week open-label period. Those who completed this period were then randomized to receive more Onabot or a placebo in a 10 -week double-blind period. Serum samples for immunogenicity were taken at baseline and at study exit. Of the 214 subjects enrolled, 170 enrolled into the placebo-controlled study period. The study concluded that the antibody status of the subjects at baseline was not a clear predictor of response to treatment.

Chinnapongse et $\mathrm{al}^{33}$ studied whether antibodies to Rimabot impact the efficacy and safety of its use in treatment of CD. A total of 1,134 subjects' data were collected in four separate clinical trials. Rimabot injections were given every 3 months, and their efficacy, immunogenicity, and safety were assessed. Cross-sectional and longitudinal statistical analyses were performed to compare efficacy at each time point, and were assessed before and after seroconversion. The study found no correlation between antibody status and rate of clinical response or safety profile.

Given the absence of any clear correlation between presence or absence of antibodies and secondary treatment failure, the clinical significance of neutralizing antibodies remains unclear.

\section{Conclusion}

Overall, there are many studies that demonstrate the efficacy and safety of each of the brands of botulinum toxins used in clinical practice. However, the determination of dosing equivalencies among these brands and serotypes has been complex with inconsistencies among the studies. When switching from one brand to another, the clinician should be aware of these issues, and not make the assumption that such ratios exist. Tailoring the dosage of each brand of BoNT to the clinical situation is the most prudent treatment strategy rather than focusing closely on conversion factors and concerns for immunogenicity.

\section{Disclosure}

Dr Comella serves on the editorial board of Clinical Neuropharmacology, Sleep Medicine, and Continuum. She receives research support from the NIH R01NS074343, U54NS065701, Dystonia Medical Research Foundation, Allergan Inc., Ipsen Biopharmaceuticals, Inc., Merz Pharmaceuticals, and Biotie Inc. She receives compensation/honoraria for services as a consultant or an advisory committee member: Acorda Therapeutics, Allergan, Inc., Impax Pharmaceuticals, Ipsen Biopharmaceuticals, Inc., Lundbeck Ltd., Medtronic Inc., Merz Pharmaceuticals, Acadia Pharmaceuticals, Teva Neurosciences, Neurocrine Biosciences Inc., Revance Therapeutic, and Ultragenyx Pharmaceuticals. She receives royalties from Cambridge, Humana Press, and Wolters Kluwer. She receives research support from the Parkinson's Disease Foundation. The authors report no other conflicts of interest in this work.

\section{References}

1. Aoki KR, Guyer B. Botulinum toxin type A and other botulinum toxin serotypes: a comparative review of biochemical and pharmacological actions. Eur J Neurol. 2001;8 Supp1 5:21-29.

2. Mills RR, Pagan FL. Patient considerations in the treatment of cervical dystonia: focus on botulinum toxin type A. Patient Prefer Adherence. 2015;9:725-731.

3. Pathak SS, Gupta RK. Botulinum toxin: from a deadly toxin to a useful drug. J MGMIS. 2009;14:10-17.

4. Brashear A, Lew MF, Dykstra DD, et al. Safety and efficacy of NeuroBloc (botulinum toxin type B) in type A-responsive cervical dystonia. Neurology. 1999;53:1439-1446.

5. Wohlfarth K, Kampe K, Bigalke H. Pharmacokinetic properties of different formulations of botulinum neurotoxin type A. Mov Disord. 2004;19 Suppl 8:S65-S67.

6. Hambleton P, Pickett AM. Potency equivalence of botulinum toxin preparations. J R Soc Med. 1994;87:719.

7. Nussgens Z, Roggenkamper P. Comparison of two botulinum-toxin preparations in the treatment of essential blepharospasm. Graefes Arch Clin Exp Ophthalmol. 1997;235:197-199.

8. Sampaio C, Ferreira JJ, Simoes F, et al. DYSBOT: a single-blind, randomized parallel study to determine whether any differences can be detected in the efficacy and tolerability of two formulations of botulinum toxin type A - Dysport and Botox - assuming a ratio of $4: 1$. Mov Disord. 1997;12:1013-1018.

9. Odergren T, Hjaltason H, Kaakkola S, et al. A double blind, randomised, parallel group study to investigate the dose equivalence of Dysport and Botox in the treatment of cervical dystonia. J Neurol Neurosurg Psychiatry. 1998;64:6-12.

10. Wohlfarth K, Schwandt I, Wegner F, et al. Biological activity of two botulinum toxin type A complexes (Dysport and Botox) in volunteers: a double-blind, randomized, dose-ranging study. J Neurol. 2008; 255:1932-1939.

11. Kranz G, Haubenberger D, Voller B, et al. Respective potencies of Botox and Dysport in a human skin model: a randomized, double-blind study. Mov Disord. 2009;24:231-236.

12. Rystedt A, Zetterberg L, Burman J, Nyholm D, Johansson A. A comparison of Botox $100 \mathrm{U} / \mathrm{mL}$ and Dysport $100 \mathrm{U} / \mathrm{mL}$ using dose conversion ratio $1: 3$ and $1: 1.7$ in the treatment of cervical dystonia: a double-blind, randomized, crossover trial. Clin Neuropharmacol. 2015;38:170-176.

13. Bentivoglio AR, Ialongo T, Bove F, De Nigris F, Fasano A. Retrospective evaluation of the dose equivalence of $\operatorname{Botox}((\mathrm{R}))$ and Dysport $((\mathrm{R}))$ in the management of blepharospasm and hemifacial spasm: a novel paradigm for a never ending story. Neurol Sci. 2012;33: 261-267.

14. Bentivoglio AR, Fasano A, Ialongo T, Soleti F, Lo Fermo S, Albanese A. Fifteen-year experience in treating blepharospasm with Botox or Dysport: same toxin, two drugs. Neurotox Res. 2009;15: 224-231.

15. Benecke R, Jost WH, Kanovsky P, Ruzicka E, Comes G, Grafe S. A new botulinum toxin type A free of complexing proteins for treatment of cervical dystonia. Neurology. 2005;64:1949-1951. 
16. Wabbels B, Reichel G, Fulford-Smith A, Wright N, Roggenkamper P. Double-blind, randomised, parallel group pilot study comparing two botulinum toxin type A products for the treatment of blepharospasm. J Neural Transm. 2011;118:233-239.

17. Saad J, Gourdeau A. A direct comparison of onabotulinumtoxina (Botox) and IncobotulinumtoxinA (Xeomin) in the treatment of benign essential blepharospasm: a split-face technique. J Neuroophthalmol. 2014;34:233-236.

18. Kollewe K, Mohammadi B, Kohler S, Pickenbrock H, Dengler R, Dressler D. Blepharospasm: long-term treatment with either Botox $(\mathrm{R})$, Xeomin(R) or Dysport(R). J Neural Transm. 2015;122:427-431.

19. Dressler D, Tacik P, Adib Saberi F. Botulinum toxin therapy of cervical dystonia: comparing onabotulinumtoxinA (Botox $((\mathrm{R})))$ and incobotulinumtoxinA (Xeomin ((R))). J Neural Transm. 2014;121:29-31.

20. Sloop RR, Cole BA, Escutin RO. Human response to botulinum toxin injection: type B compared with type A. Neurology. 1997;49:189-194.

21. Comella CL, Jankovic J, Shannon KM, et al. Comparison of botulinum toxin serotypes A and B for the treatment of cervical dystonia. Neurology. 2005;65:1423-1429.

22. Pappert EJ, Germanson T; Myobloc/Neurobloc European Cervical Dystonia Study Group. Botulinum toxin type B vs. type A in toxin-naive patients with cervical dystonia: randomized, double-blind, noninferiority trial. Mov Disord. 2008;23:510-517.

23. Brin MF, Lew MF, Adler CH, et al. Safety and efficacy of NeuroBloc (botulinum toxin type B) in type A-resistant cervical dystonia. Neurology. 1999;53:1431-1438.

24. Bihari K. Safety, effectiveness, and duration of effect of BOTOX after switching from Dysport for blepharospasm, cervical dystonia, and hemifacial spasm dystonia, and hemifacial spasm. Curr Med Res Opin. $2005 ; 21: 433-438$

25. Marchetti A, Magar R, Findley L, et al. Retrospective evaluation of the dose of Dysport and BOTOX in the management of cervical dystonia and blepharospasm: the REAL DOSE study. Mov Disord. 2005;20: 937-944.
26. Dutton JJ, White JJ, Richard MJ. Myobloc for the treatment of benign essential blepharospasm in patients refractory to botox. Ophthal Plast Reconstr Surg. 2006;22:173-177.

27. Benecke R. Clinical relevance of botulinum toxin immunogenicity. BioDrugs. 2012;26:e1-e9.

28. Jankovic J, Hunter C, Dolimbek BZ, et al. Clinico-immunologic aspects of botulinum toxin type B treatment of cervical dystonia. Neurology. 2006;67:2233-2235.

29. Kranz G, Sycha T, Voller B, Kranz GS, Schnider P, Auff E. Neutralizing antibodies in dystonic patients who still respond well to botulinum toxin type A. Neurology. 2008;70:133-136.

30. Brin MF, Comella CL, Jankovic J, Lai F, Naumann M; Group CDBS. Long-term treatment with botulinum toxin type A in cervical dystonia has low immunogenicity by mouse protection assay. Mov Disord. 2008; 23:1353-1360.

31. Lange O, Bigalke H, Dengler R, Wegner F, deGroot M, Wohlfarth K. Neutralizing antibodies and secondary therapy failure after treatment with botulinum toxin type A: much ado about nothing? Clin Neuropharmacol. 2009;32:213-218.

32. Charles D, Brashear A, Hauser RA, et al. Efficacy, tolerability, and immunogenicity of onabotulinumtoxina in a randomized, double-blind, placebo-controlled trial for cervical dystonia. Clin Neuropharmacol. 2012;35:208-214

33. Chinnapongse RB, Lew MF, Ferreira JJ, Gullo KL, Nemeth PR, Zhang Y. Immunogenicity and long-term efficacy of botulinum toxin type B in the treatment of cervical dystonia: report of 4 prospective, multicenter trials. Clin Neuropharmacol. 2012;35:215-223.

34. Ranoux D, Gury C, Fondarai J, Mas JL, Zuber M. Respective potencies of Botox and Dysport: a double blind, randomised, crossover study in cervical dystonia. J Neurol Neurosurg Psychiatry. 2002;72(4): 459-462.

35. Badarny S, Susel Z, Honigman S. Effectivity of Dysport in patients with blepharospasm and hemifacial spasm who experienced failure with Botox. Isr Med Assoc J. 2008;10(7):520-522.
Therapeutics and Clinical Risk Management

\section{Publish your work in this journal}

Therapeutics and Clinical Risk Management is an international, peerreviewed journal of clinical therapeutics and risk management, focusing on concise rapid reporting of clinical studies in all therapeutic areas, outcomes, safety, and programs for the effective, safe, and sustained use of medicines. This journal is indexed on PubMed Central, CAS,

\section{Dovepress}

EMBase, Scopus and the Elsevier Bibliographic databases. The manuscript management system is completely online and includes a very quick and fair peer-review system, which is all easy to use. Visit http://www.dovepress.com/testimonials.php to read real quotes from published authors. 